\title{
A Direct Demonstration of Functional Specialization in Human Visual Cortex
}

\author{
S. Zeki, ${ }^{1}$ J. D. G. Watson, ${ }^{1,2,3}$ C. J. Lueck, ${ }^{4}$ K. J. Friston, ${ }^{2}$ C. Kennard, ${ }^{4}$ and R. S. J. Frackowiak ${ }^{2.3}$ \\ 'Department of Anatomy, University College, London WC1E 6BT, United Kingdom, ${ }^{2}$ MRC Cyclotron Unit, Hammersmith \\ Hospital, London W12 OHS, United Kingdom, IInstitute of Neurology, Queen Square, London WC1N3BG, United Kingdom, \\ and ${ }^{4}$ Department of Neurology, The London Hospital, London E1 1BB, United Kingdom.
}

\begin{abstract}
We have used positron emission tomography (PET), which measures regional cerebral blood flow (rCBF), to demonstrate directly the specialization of function in the normal human visual cortex. A novel technique, statistical parametric mapping, was used to detect foci of significant change in cerebral blood flow within the prestriate cortex, in order to localize those parts involved in the perception of color and visual motion. For color, we stimulated the subjects with a multicolored abstract display containing no recognizable objects (Land color Mondrian) and contrasted the resulting blood flow maps with those obtained when subjects viewed an identical display consisting of equiluminous shades of gray. The comparison identified a unique area (area V4) located in the lingual and fusiform gyri of the prestriate cortex. For motion, blood flow maps when subjects viewed moving or stationary black and white random-square patterns were contrasted. The comparison identified a unique area located in the region of the temporo-parieto-occipital junction (area V5). We thus provide direct evidence to show that, just as in the macaque monkey, different areas of the human prestriate visual cortex are specialized for different attributes of vision. The striate cortex (V1) and the contiguous visual area (V2), which in the monkey brain feed both the homologous areas, were active in all 4 conditions. This pattern of activity allowed us to use an extension of the approach to assess the functional relationship between the 3 areas during color and motion stimulation. This is based on an hypothesis-led analysis of the covariance structure of the blood flow maps and promises to be a powerful tool for inferring anatomical pathways in the normal human brain. In this study, we were able to demonstrate a positive functional relationship between areas $V 1 / V 2$ and $V 4$ during color vision and areas $V 1 / V_{2}$ and $V 5$ during motion stimulation, reflecting the anatomical connections between these areas in the macaque monkey.
\end{abstract}

The concept of functional specialization in the cerebral cortex can be traced back to the beginnings of modern neurology in the middle of the last century when Broca (1861) in France and

\footnotetext{
Received Apr. 2, 1990; revised Oct. 2, 1990; accepted Oct. 5, 1990.

We are grateful to members of the Radiochemistry and PET Scientific Sections of the Cyclotron Unit and to Ms. C. Taylor and Mr. G. Lewington, who made these studies possible. We thank our normal volunteers for their time. The Wellcome Trust supported this work and the salaries of C.J.L. and K.J.F.

Correspondence should be addressed to S. Zeki or R. S. J. Frackowiak at the above addresses.

Copyright (c) 1991 Society for Neuroscience 0270-6474/91/110641-09\$03.00/0
}

Fritsch and Hitzig (1870) in Germany firmly established its foundations by showing that the integrity of specific, separate cortical areas is necessary for the production of articulate speech and voluntary movement. Subsequent work charting and defining the many cortical areas associated with different functions has been a triumph of neurology. By the 1930s, Lashley could write that "in the field of neurophysiology no fact is more firmly established than the functional differentiation of various parts of the cerebral cortex. ... No one to-day can seriously believe that the different parts of the cerebral cortex all have the same functions or can entertain for a moment the proposition of Hermann that because the mind is a unit the brain must also act as a unit" (Lashley, 1931).

Yet, it is the very unitary nature of the visual image in the brain, one in which the different attributes of the visual sceneform, color, motion, depth - are seen in precise spatiotemporal registration, that was to conceal the profound division of labor within the visual cortex. The error was reinforced by the anatomical organization of the visual pathways. The cortical input from the retina is funneled through the striate cortex [Henschen's "cortical retina" (1930)], lesions in which lead to absolute blindness, usually without dissociation of visual submodalities. It therefore seemed natural to Holmes $(1918,1945)$ and others (Monbrun, 1939; Teuber et al., 1960; Duke-Elder, 1971) to consider that the striate cortex (area V1) was the sole visual "perceptive center" in humans, while the cortex surrounding it associated the "received" visual "impressions," contrasting them with previous "impressions" of a similar kind (for review, see Zeki, 1990a). Thus, the suggestion, based on imperfect early clinical evidence (Verrey, 1888; Mackay and Dunlop, 1899), that a specific region of this "association" cortex in the lingual and fusiform gyri (which, at that time, were considered by some to be part of the primary visual receptive center) may be specialized for color, considered to be a visual impression, seemed improbable. Henschen (1930) wrote that, if this view were true, then "with the striate cortex destroyed and with cortex of that other gyrus [lingual and fusiform] intact, a patient would have to be absolutely blind and yet be able to see colors, which makes no sense." Further evidence in favor of functional specialization in the occipital cortex was repeatedly discounted and, indeed, the concept "vanished" from the clinical literature (Damasio, 1985).

The concept of functional specialization in the visual cortex is therefore more recent (Zeki, 1974a, 1978a). It is based on studies of the macaque monkey, which show that, of the many visual areas (Cragg, 1969; Zeki, 1969, 1971) that lie outside the striate cortex, one area (V5) is specialized for visual motion, 
while another, anatomically distinct area (V4) is specialized for color (Zeki, 1973, 1974b, 1977). Following this discovery, renewed attempts have been made to chart the specialized visual areas in the human brain. However, the recent evidence in favor of dissociation of color and movement processing in the cerebral cortex of humans is still indirect. It is based, in part, on naturally occurring cortical lesions that give rise to an inability to see colors (achromatopsia, e.g., Pearlman et al., 1979; Damasio et al., 1980; Kolmel, 1988) or to cerebral motion blindness (Zihl et al., 1983; Thurston et al., 1988). Unfortunately, such lesions are uncontrolled and uncontrollable in their extent. It is also based, in part, on psychophysical evidence which shows that human subjects find that the perception of motion becomes difficult, and even incoherent, when asked to discriminate moving stimuli distinguished from the background on the basis of color alone, in other words, that the motion system is "color blind" (Ramachandran and Gregory, 1978; Carney et al., 1987; Ramachandran, 1987).

In this study, we wanted to demonstrate functional specialization in the normal human visual cortex directly and to chart the anatomy of the areas involved. Obviously, this requires the use of at least 2 different visual stimuli, representing 2 different submodalities, in the same study. We used the same 2 submodalities, motion and color, that were used to establish functional specialization in the monkey visual cortex (Zeki, 1973, $1974 b$ ). Our approach was to use positron emission tomography (PET) to detect significant regional changes in cerebral blood flow ( $\mathrm{rCBF}$ ) in the brains of normal human subjects when they viewed stimuli chosen to emphasize color or motion. We were encouraged by the earlier experiments of Fox et al. (1986), who showed that PET can provide an accurate picture of the position and topographic organization of the primary visual, or striate, cortex.

Preliminary reports of these results have been published (Lueck et al., 1989; Cunningham et al., 1990).

\section{Materials and Methods}

Nine normal volunteers were studied. All were male, 7 were right handed, and their ages ranged from 21 to $43 \mathrm{yr}$ (mean, $29 \mathrm{yr}$ ). Two experiments were performed. In the first, 6 subjects were stimulated with colored and isoluminant gray-shaded abstract displays occupying the central $40^{\circ}$ of the field of view. In the second, the other 3 subjects were presented with a random array of stationary or moving small black and white squares. All subjects gave informed written consent, and the studies were approved by the Hammersmith Hospital Ethics Committee. Permission to administer radiation was obtained from the Administration of Radioactive Substances Advisory Committee of the Department of Health, U.K.

Paradigm design. Both experiments involved 6 sequential measurements of $\mathrm{rCBF}$ during the presentation of different visual stimuli. Also in both experiments, 3 different stimuli were presented in balanced order (ABCCBA) to remove time and habituation effects. The stimuli were as follows.
Experiment 1-Stimulus A: Eyes closed. Stimulus B: Eyes open, with the central $40^{\circ}$ occupied by an abstract display of 15 multicolored squares and rectangles (Land color Mondrian; Land, 1974). Stimulus C: Eyes open, with the central field occupied by an isoluminant gray shaded version of the colored Mondrian presented in stimulus B.

Experiment 2-Stimulus A: eyes closed. Stimulus B: Eyes open, with the central field occupied by a stationary display of black and white random squares. Stimulus C: Eyes open, with the same display moving in a random direction every $5 \mathrm{sec}$.

The visual stimuli. Displays were generated on a high-resolution AMI$\mathrm{GA}$ monitor (Commodore Computers Inc.), presented at a viewing distance of $47 \mathrm{~cm}$ and occupying the central $40^{\circ}$ of the field of view. The Mondrian we used was a collage of 15 squares and rectangles of different shapes and colors, assembled to form an abstract scene with no recognizable objects, thus minimizing the role of memory and learning. No area of the Mondrian was surrounded by another area of single color only, thus eliminating any effects that might be attributable to induced colors or to color contrasts. The isoluminant gray values were determined in a separate calibration experiment in which each of the colors from the Mondrian was individually displayed in the form of a vertical grating alternating temporally with a gray grating at a frequency of $5 \mathrm{~Hz}$. The luminance of the gray grating was gradually varied until the illusory perception of motion ceased. This was taken to be the isoluminant value for that color (Anstis and Cavanagh, 1983). The procedure was repeated for each color in turn, and a gray replica of the color Mondrian was thus constructed. With each rectangle isoluminant with its color counterpart, the only difference between the color and the gray displays was the absence of color in the latter.

For motion, we used 2 versions of a black and white random-square pattern in which an array of approximately 100 small black squares, each subtending $1^{\circ}$, were displayed on a white background. The display could be stationary or moving. When in motion, all the squares moved constantly at a rate of $6 \% \mathrm{sec}$, in 1 of 8 directions, ranging from $0^{\circ}$ to $315^{\circ}$ in steps of $45^{\circ}$. The direction of motion was changed every $5 \mathrm{sec}$. To prevent visual adaptation and fading, subjects were asked to move their eyes back and forth slowly along a horizontal boundary line subtending approximately $5^{\circ}$ over the central part of the field of view in the color experiment, and to fixate on a small stationary square during the motion experiment.

Blood flow measurement. Cerebral blood flow was measured with the dynamic/integral technique described by Lammertsma et al. (1990), of which a brief account follows. Subjects inhaled trace quantities of $\mathrm{C}^{15} \mathrm{O}_{2}$ provided at a concentration of $6 \mathrm{MBq} / \mathrm{ml}$ and a flow rate of $500 \mathrm{ml} /$ min through a standard oxygen face mask for a period of $2 \mathrm{~min}$. The effective dose equivalent of each administration was $1.2 \mathrm{mSv}$. Twentyone successive dynamic PET scans were collected within a period of $3.5 \mathrm{~min}$, starting $0.5 \mathrm{~min}$ before administration of the flow tracer $\left(\mathrm{C}^{15} \mathrm{O}_{2}\right)$. Stimuli were administered throughout the period of scanning, though the blood flow maps were constructed only from the integral of tissue activity recorded for the $2 \mathrm{~min}$ after commencing administration of tracer. Absolute blood flow measurements could then be calculated from the second-by-second radioactivity measurements recorded from a small radial artery cannula during scanning, corrected by reference to the series of dynamic PET scans. The latter is necessary to correct for the distortion of the radial artery counts relative to the true activity profile entering the brain due to dispersion and delay of the blood in the brachial artery and cannula before it reaches the radiation detector. The corrected arterial input function and the integrated counts in the brain were used to derive the quantitative parametric images of rCBF. Scanning of activity in the tissues of the brain was performed using a CTI $931 / 08 / 12$ PET scanner (CTI Inc., Knoxville, TN), whose physical characteristics

Figure 1. Projections onto the lateral and medial surfaces of the brain (top) and coronal, sagittal, and transverse projections (bottom) of statistical parametric maps obtaincd by planned comparison of means between conditions with eyes closed (rest) and those with eyes open (color and gray). All areas of significant increase in rCBF are shown in the lower images, projected onto the transverse, coronal, and sagittal planes. The grid is the standard proportional stereotactic grid of Talairach and Tournoux (1988), which defines the 3-D space into which all the subjects' brains have been rescaled (normalized). The contours of the brain in the transverse plane at the level of the ACPC line (bottom), the midsagittal plane (upper $l e f t$, and the coronal plane at the midpoint of the ACPC line are shown on the respective grids. This display permits rapid inspection and localization of all the data. The white and red end of the color scale (distributed over 255 levels) shows areas of maximally significant $\mathrm{rCBF}$ change, and the blue and green end shows the threshold of $p<0.05$. The striate and prestriate areas show highly significant changes in $\mathrm{ICBF}$. The upper images are projected onto the medial and lateral surfaces of the brain to illustrate more clearly the extent of significant change in rCBF. It is clear that, in 

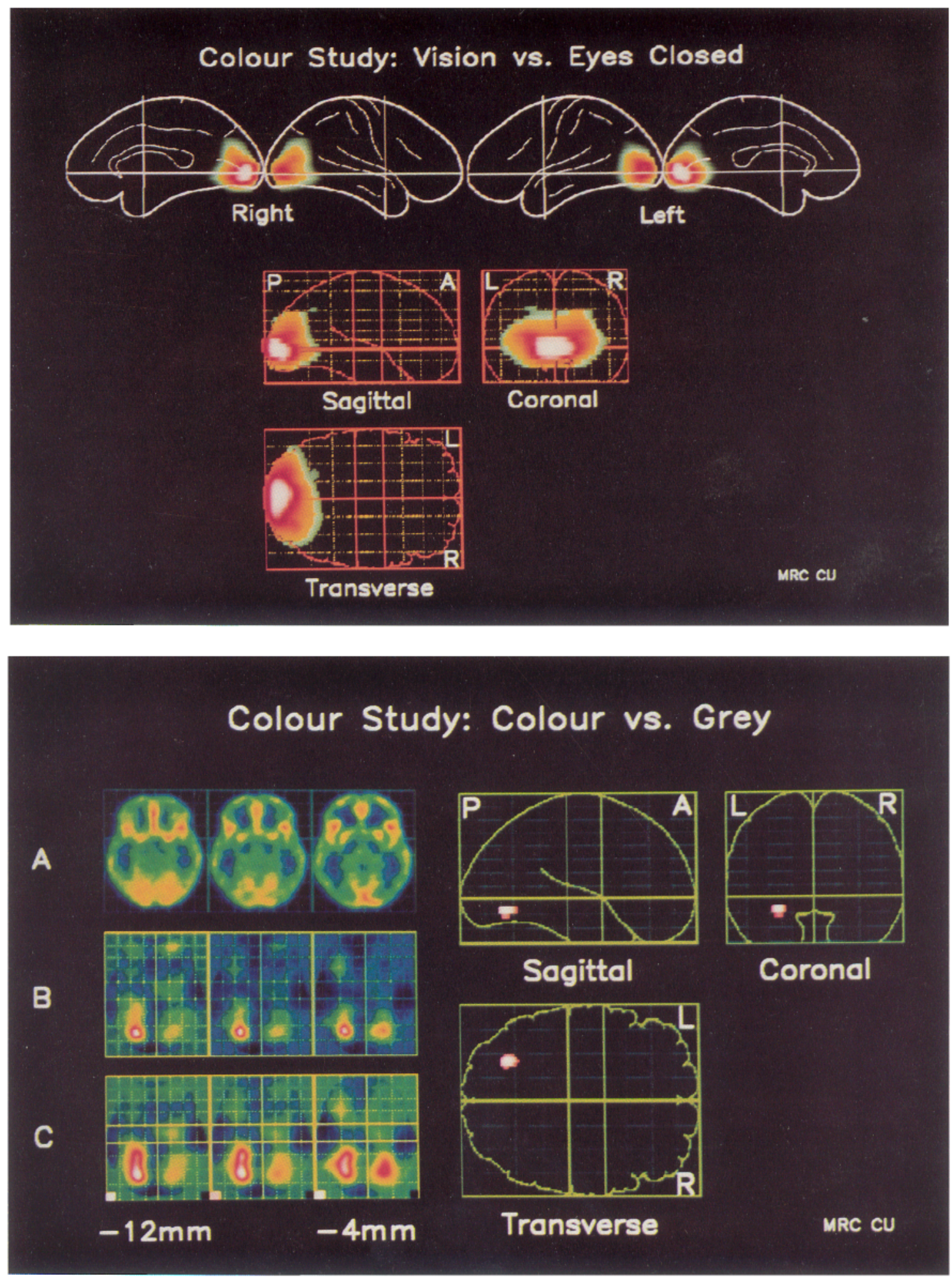

addition to the striate area, the cuneate gyrus above and the fusiform and lingual gyri below have been stimulated, as has the immediate peristriate area back to the occipital pole. Parts of this area have been identified as responsible for color perception, others represent the primary visual cortex, and the remainder (or a major part of it) must represent the human equivalent of V2.

Figure 2. Data from the color experiment. On the left are transverse images of the brain at planes $-12,-8$, and $-4 \mathrm{~mm}$ relative to the ACPC line. $A$, Anatomical features averaged from the 6 subjects into Talairach space. $B$, The arithmetical difference between adjusted mean blood flows for color and gray stimuli. $C$, The SPMs derived from a formal comparison of the adjusted mean blood flows and variances for each of the 2 conditions. The color-coding conventions are arbitrary and similar to Figure 1. On the right are the orthogonal projections of the statistical comparison at a threshold of $p<0.05$ (corrected for multiple comparisons). The areas showing increased flow, subserving the perception of color, are located inferiorly and medially in the occipital cortex (V4). 
have been described elsewhere (Spinks et al., 1988). The scanner collects data in 15 planes covering an axial field of view of $10.13 \mathrm{~cm}$, with no interplane dead space. This permits imaging of the brain from cerebellum to vertex with a resolution of $8.5 \times 8.5 \times 7.0 \mathrm{~mm}$ at full width half-maximum (FWHM), following reconstruction with a Hanning filter of cut-off frequency 0.5 . The reconstructed data of each plane were displayed in a $128 \times 128$-pixel format, with cach pixcl $2.05 \times 2.05$ $\mathrm{mm}$.

Image analysis. All calculations and image matrix manipulations were carried out on Sun 3/60 computers (Sun Computers Inc. using ANALYZE image display software (BRU, Mayo Foundation) and pRomatLaB (Mathworks Inc.).

The 15 original scan slices of each data set $(6.75-\mathrm{mm}$ interplane distance) were transformed using bilinear interpolation into a standard stereotactic space, corresponding to the atlas of Talairach and Tournoux (1988). The intercommissural line was identified directly from the PET images according to a previously described method (Friston et al., 1989). To increase the signal-to-noise ratio and to allow summation between locally dispersed sites of activation from different individuals, each image was smoothed using a Gaussian filter (FWHM, 10 pixels). This dispersion is due, in large part, to normal variations in gyral shape and direction between subjects. In the standard stereotactic space, each pixel was $2 \mathrm{~mm}^{2}$, and the interplane distance corresponded to $4 \mathrm{~mm}$.

Statistical analysis. Because of the confounding effect of global changes in cerebral blood flow (CBF), the differences in global CBF between subjects were removed using an analysis of covariance (ANCOVA), as previously described (Friston et al., 1990). All analyses were performed on a pixel-by-pixel basis. This generated 6 adjusted group means and the associated error variance for each pixel. Planned comparisons of these means were performed using the $t$ statistic, the hypothesis being that some specific regions of the brain would be preferentially activated with specific types of visual stimulation. The $t$ distribution was transformed into the standard normal distribution to render the statistical parametric maps (SPMs) Gaussian. Under the null hypothesis that there will be no regional difference during visual stimulation, the SPMs are stationary; that is, their autocorrelation function (the degree of interdependency of adjacent pixel values) is the same over the entire map. The SPMs were thresholded to make a correction for the effective number of independent measures in the SPM. This is less than the number of pixels because of the smoothness resulting from reconstruction, filtering, and averaging of the images. The threshold was set to give an expected false positive every 20 planes. This threshold was determined by measuring smoothness empirically and modeling the SPM as a stationary Gaussian process (K. J. Friston et al., unpublished observations). Significant pixels $(p<0.05)$ were then displayed on coronal, sagittal, and transverse views of the brain.

The only comparable method of image analysis in the literature is that described by Fox et al. (1986). The similarities between the above approach and that of Fox et al. include the following: Both use a standard stereotactic coordinate space and attempt to remove the confounding effects of global differences in cerebral blood flow. Both are done pixel by pixel and attempt to assess significance of change using an estimate of error variance. The major differences include the following: our approach removes global variance statistically, by an analysis of covariance, rather than by a simple proportional normalization, by division of pixel values by whole-brain mean flow. Our estimation of error variance is longitudinal, across subjects for each stimulus, and performed independently for each pixel in the image. Our approach thus accounts for regional changes in error variance, or the "reliability" of the regional responses to physiological activation. The resultant images (SPMs), reflecting differences in activation, are statistical in a formal sense in that they reflect significance of local change irrespective of changes elsewhere. Finally, the findings are accepted as significant only if they survive a correction for the effective number of pixels analyzed. In contrast, the method of Fox et al. (1986) determines the variance in pixels across the entire brain resulting from the subtraction of 2 conditions. It is tested in a global sense for deviation from the normal distribution, and if a significant difference is found, outliers are identified by thresholding.

Planned comparison of differences. Two planned comparisons were made in each experiment (color and motion). First, a comparison was made of the condition with the key visual component, color or motion, and the corresponding control, gray or stationary. Second, a comparison of vision with nonvision, that is, the middle 4 condition means with the first and last, was performed. These comparisons were intended to identify specific cortical areas critically concerned with the modality in question (color or motion) and also the cortex implicated more generally in vision.

To estimate the size, as opposed to significance, of the increases, the adjusted group rCBFs for the different stimuli were compared at locations identified by maxima in the SPM. Because the original scans were smoothed, these adjusted pixel values correspond to the adjusted mean rCBF of a $20-\mathrm{mm}$ region centered on the chosen pixel.

Analysis of covariance structure. In order to investigate further the relationship of distributed brain systems underlying vision, covariance SPMs were generated. Our aim was to make inferences about anatomical connections between the areas activated in the study. The maps were designed to show which areas covaried systematically with the $\mathrm{rCBF}$ variation of a reference pixel in a chosen area, for example, V4. This analysis assumes that the brain is composed of certain regions whose activity is specifically perturbed (up or down) by aspects of vision and of other areas whose activity is independent, with no relation to the visual stimuli presented. With a particular function such as vision, regions collectively involved must constitute a highly covarying network. By choosing a reference pixel in one region within this system, the remaining components of the system should be identified in the corresponding covariance SPM. Clearly, this approach is descriptive and must be hypothesis led.

Five reference pixels were identified, their locations indicated by the position of maxima in the contrast SPMs. These pixels were in the striate cortex (V1), the color centers (V4), and the motion centers (V5) in both hemispheres.

\section{Results}

\section{Comparison of conditions}

The cortical areas activated nonspecifically by vision were centered on, and coextensive with, the striatc and immediate peristriate cortex. Because we could not distinguish a boundary between $\mathrm{V} 1$ and the contiguous visual area $\mathrm{V} 2$, we refer to this zone as $\mathrm{V} 1 / \mathrm{V} 2$ in this paper. No other brain regions showed increased rCBF of such high significance. The results of this first comparison for the color and the motion study were qualitatively equivalent, and therefore only the SPM from the color study is shown in Figure 1.

In the first experiment, comparison of color and gray scans demonstrated a focal, bilateral activation in the lingual and fusiform gyri on the inferior and medial aspects of the occipital lobes (Fig. 2). We refer to this area as area V4. Although both sides are clearly shown, the statistical analysis indicates a lateralization of function to the left, as suggested in our preliminary communication on 3 subjects (Lueck et al., 1989).

In the second experiment, comparison of moving and stationary displays demonstrated a focal, bilateral activation at the confluence of temporal, parietal, and occipital cortices situated laterally on the cortical convexity (Fig. 3), approximately at the junction of Brodmann's areas 19 and 37. We refer to this area as area V5.

The dissociation between areas that were maximally active during color and visual motion stimulation is direct evidence of functional parcellation in the human prestriate visual cortex.

\section{Quantitative changes in $r C B F$}

Locations of V1/V2, V4, and V5 (right and left) were identified from maxima in the SPMs (Figs. 1-3). These locations were used to tabulate the adjusted mean rCBF for each condition in each area. The stereotactic and rCBF data are presented in Tables 1 and 2 . The activity in the primary visual cortex was different in the 2 experiments. In the first experiment, the increase in $\mathrm{rCBF}$ in area $\mathrm{V} 1 / \mathrm{V} 2$ was $17 \%$, and, in the second, the rCBF increased by $24 \%$, presumably reflecting the difference in stimulation of the striate cortex by the Mondrians and the random-pattern stimuli. 


\section{Covariance structure}

In the first experiment, when the reference pixel was placed in either of the color centers (V4), positive covariance was demonstrated in the striate and peristriate regions (V1/V2) and contralateral color area (Fig. 4). Similarly, in the second experiment, the primary visual areas ( V / V2) covaried with the motion area (V5), as did the contralateral motion center. This suggests that $\mathrm{V} 1$ sends independent parallel outputs to V4 and to V5 and that areas V4 and V5 in one hemisphere are connected with their counterparts in the other, points taken up in the Discussion.

\section{Discussion}

The neurobiologist has obtained much information about cortical function from anatomical and single-cell electrophysiological experiments, and such experiments were the basis for the demonstration of functional specialization in the macaque monkey visual cortex (Zeki, 1974a, 1978a). To study the human brain in such detail is morc difficult, but the advent of PET has made it possible to record activity simultaneously from the entire human brain, though with limited spatial and temporal resolution. Nevertheless, the capacity to observe all cerebral areas participating in the performance of a task, or subtending a physiological function, allows us not only to localize function, but also to make inferences about functional anatomical connections. In this way, we can study an isolated system in the healthy human brain.

The main difficulty we faced in investigating the visual system was choosing appropriately specific stimuli that would activate the striate and certain prestriate visual areas, but not others. The problem was awkward because most visual stimuli will contain attributes of possible relevance to many specialized visual areas. For example, in addition to its potential effects on V4, a Mondrian contains oriented boundaries that, in the monkey, will activate cclls in arcas V 3 and V3 $\Lambda$ that are orientation selective, even though they are indifferent to the color of the stimulus (Zeki, 1978c). The solution chosen was to contrast scans obtained with stimuli identical in all respects save the one of interest. The stimuli we used, Land's Mondrian display and the moving random pattern, were designed for and had been effectively used in animal studies and human psychophysical experiments. They allowed us to demonstrate separate motion and color centers in the human prestriate visual cortex well outside the striate area, thus proving that functional specialization is an important feature of the organization of the human visual cortex. Our results also indicate that previous conclusions about the organization of the visual cortex drawn from anatomy and single-cell recording in the monkey, which is unable to communicate a percept such as color verbally, are valid for the human brain.

\section{The color center (area V4)}

The data show that, when comparing brain activity during color and gray stimulation, the only area showing a significant change of activity was in the region of the lingual and fusiform gyri. This area lies outside the striate cortex and is the same area implicated in achromatopsia (cerebral color blindness) by clinical studies (Verrey, 1888; Mackay and Dunlop, 1899; Lcnz, 1921; Pearlman et al., 1979; Damasio et al., 1980; Kolmel, 1988; Sacks et al., 1988). The clinical literature is unclear as to whether the color center lies in both gyri or is restricted to only one. Verrey (1888) located it in both, which he mistakenly considered to be part of the primary visual cortex. Mackay and Dunlop (1899), on the other hand, located it in the fusiform gyrus. A similar location can be inferred from the work of Lenz (1921), whose patient was examined postmortem in the greatest detail. Unfortunately, our data do not clarify the problem further, except that the coordinates of the area of maximal change of rCBF lie in the fusiform gyrus. In the macaque monkey, V4 is well removed from V1 by other areas, in particular area V2, throughout most of its extent. It comes closest to V1 in the region of foveal representation of the latter (Zeki, 1971). The topographical arrangement of visual areas is somewhat different in humans, but it would be reasonable to expect that V2, which surrounds human V1 throughout most of its extent (Horton and Hedley-Whyte, 1984), would be one area interposed between $\mathrm{V} 1$ and the human homologue of V4. If so, then the inferior portion of V2 should lie in the lingual gyrus, because the striate cortex emerges inferiorly from the calcarine sulcus onto it. Hence, the fusiform gyrus is a more likely location for the color center, but the precise localization difficulty is magnified by the variability of the sulcal and gyral pattern in this part of the occipital lobe from subject to subject.

\section{The motion center (area V5)}

As shown in the second experiment, the area of significantly changed rCBF during motion stimulation was well removed from area V4. It was located more laterally and superiorly, at the junction of parietal and occipital cortices (the junction of Brodmann's cytoarchitectonic areas 19 and 37). As far as we can tell, this is similar to the site of activation reported in abstract by Miezin et al. (1987).

The topographical separation between V5 and V4 is impressive. It allows us to determine directly, with certainty, that functional specialization is an organizational feature of the human visual cortex. V5, as demonstrated in this study, was much smaller than the extent of the lesion leading to cerebral motion blindness in the unique patient of Zihl et al. (1983). Macaque V5 is surrounded by satellite areas also involved with visual motion, but in different ways (Zeki, 1980; Desimone and Ungerleider, 1986; Komatsu and Wurtz, 1988; Tanaka et al., 1986). It is possible that, with the use of a greater repertoire of specific stimuli, motion-sensitive cortex surrounding V5 may be demonstrated in the future.

While we refer to human V4 and V 5 as the color and motion centers, respectively, we do not wish to imply that the processing of color or motion is necessarily their only function, or that these are the only areas involved with those submodalities of vision. We state only that color and motion are among their chief functions. Indeed, in the macaque monkey, both V4 and V5 are parts of more extensive pathways that include other areas. The motion pathways include areas $\mathrm{V} 1$ and $\mathrm{V} 2$ in addition to V5, as well as areas in the parietal and temporal cortices. In addition to V4, the color pathways include V1 and V2 and other regions of the temporal and parietal cortices (Zeki and Shipp, 1988). That the parietal and inferior temporal cortices were not significantly activated in our experiments almost certainly reflects the fact that we chose the simplest possible visual stimuli. For color, the stimuli were designed to minimize any effect of memory and learning, both of which may be important functions of the inferior temporal cortex. For motion, factors such as absolute and relative position, important functions of the parietal cortex, were controlled out. Corbetta et al. (1990) have 


\section{Motion Study: Motion vs. Stationary}

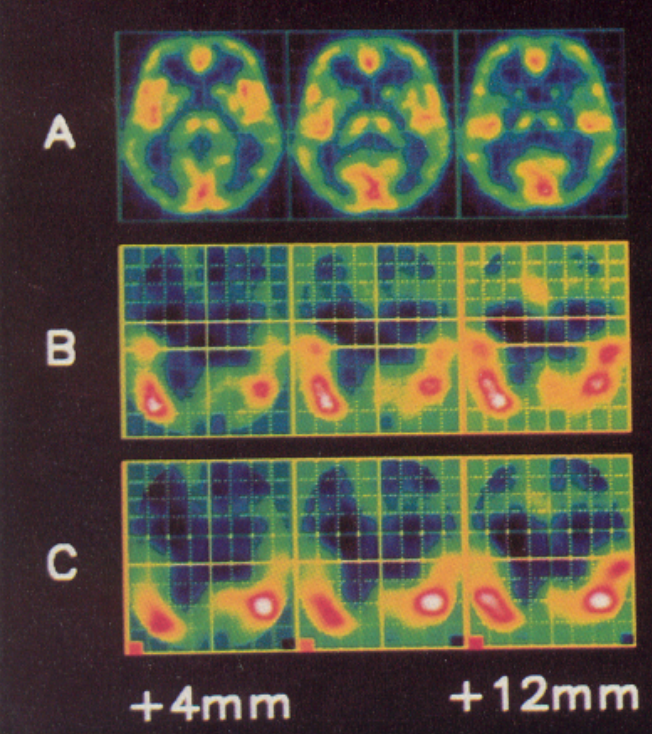

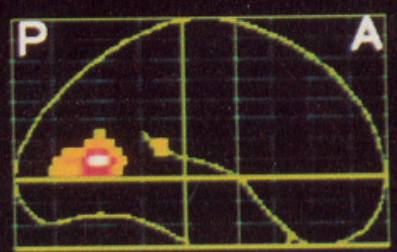

Sagittal

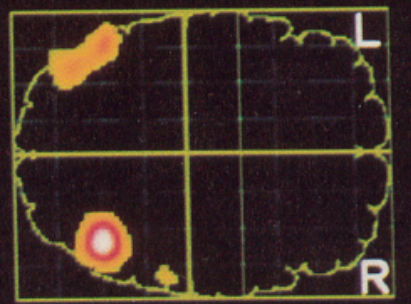

Transverse

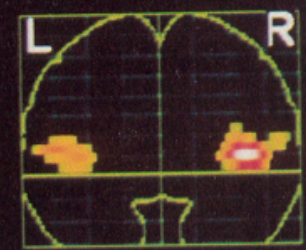

Coronal

MRC CU

Figure 3. Data from the visual motion experiment, with conventions identical to Figure 2 and spanning planes +4 to +12 mm relative to the ACPC line. The map shows areas specifically subserving the perception of movement in the visual scene (V5). The areas are located on the convexity of the prestriate cortex at the junction of areas 19 and 37 of Brodmann.

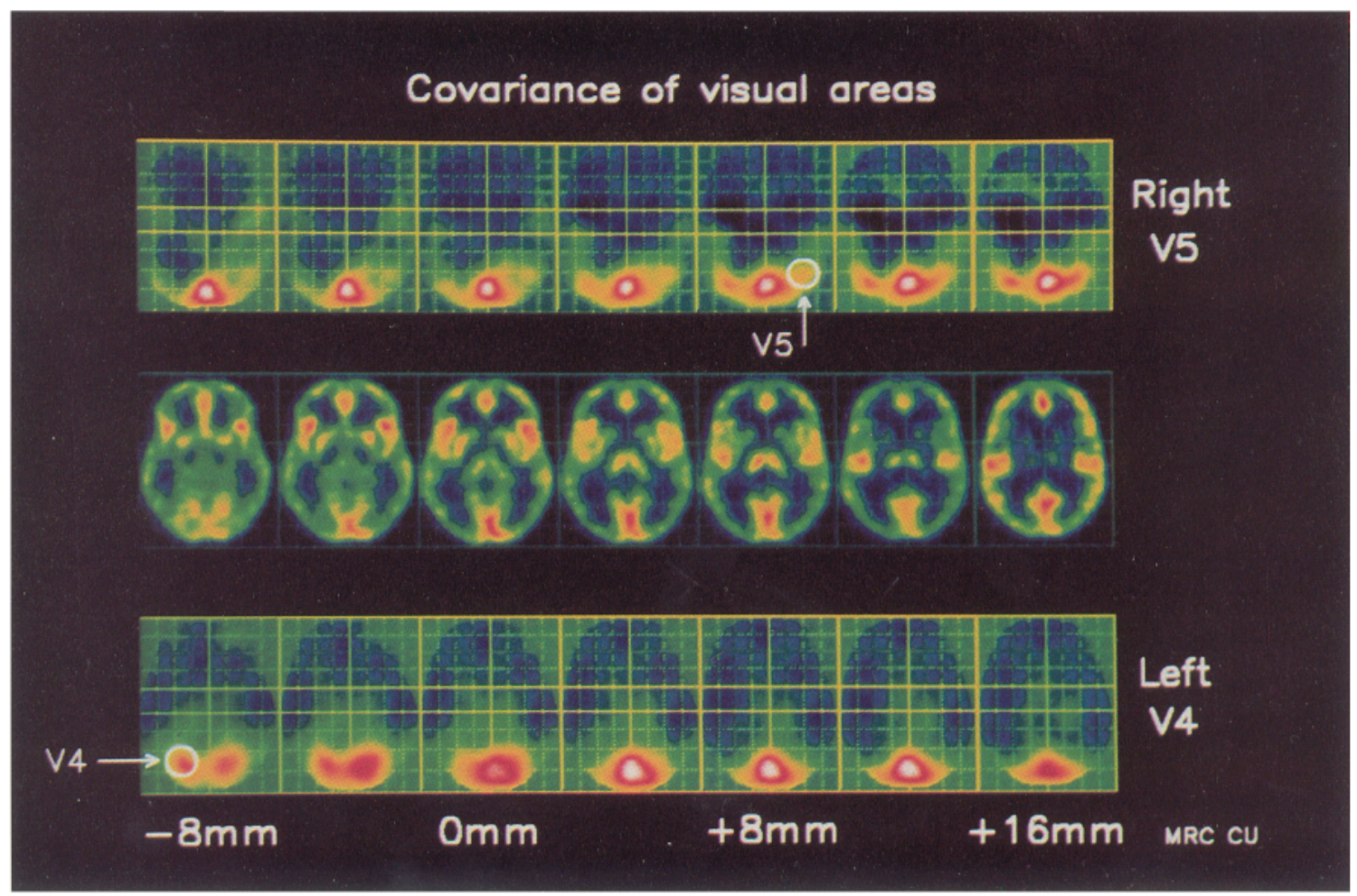

Figure 4. Transverse sections of covariance maps for motion (top) and color (bottom) experiments. In the middle row, to orient with respect to anatomical detail, is the average of the PET images for the 6 color subjects, for all conditions. To generate these covariance maps, a pixel within the ringed areas (V4 or V5) was chosen as the reference point (coordinates in Tables 1 and 2). The positive covariation of other pixels with the chosen pixel was used to generate the maps. For example, when the chosen pixel was within V4 (lower row), the positive covariation was with its homologue on the other side and the V1/V2 complex. No other cortical area covaried positively. When the chosen pixel was in the right V5, the positive covariation was only with its opposite homologue and the V1/V2 complex. Identical results were obtained if the reference pixel was placed in the right V4 or the left V5. 
Table 1. Experiment 1: color versus gray

\begin{tabular}{|c|c|c|c|c|c|}
\hline \multirow[b]{2}{*}{ Region } & \multicolumn{3}{|c|}{$\begin{array}{l}\text { CBF (adjusted group } \\
\text { means; } \mathrm{ml} \mathrm{dl}^{-1} \min ^{-1} \text { ) }\end{array}$} & \multirow{2}{*}{$\begin{array}{l}\text { Talairach } \\
\text { coordinates }^{a}\end{array}$} & \multirow[b]{2}{*}{$Z$ score } \\
\hline & Rest & Gray & Color & & \\
\hline Right V4 & 59 & 62 & 64 & $+20,-66,-4$ & $2.90^{*}$ \\
\hline Left V4 & 65 & 65 & 68 & $-26,-68,-8$ & 3.93 \\
\hline Mean & 62 & 63 & 66 & & \\
\hline Right V5 & 51 & 51 & 52 & & \\
\hline Left V5 & 46 & 49 & 48 & & \\
\hline Mean & 49 & 50 & 50 & & \\
\hline $\mathrm{V} 1 / \mathrm{V} 2$ & 62 & 72 & 72 & $-4,-90,0$ & 13.0 \\
\hline
\end{tabular}

Adjusted group mean rCBF for each condition (averaged from 2 estimations for each of the 3 physiological states) in the areas indicated in the SPMs to have shown significant rCBF change (at $p<0.05$ level) for color versus gray. Flow values have been normalized by ANCOVA to a mean flow of $50 \mathrm{ml} \mathrm{dl}^{-1} \mathrm{~min}^{-1}$. Loci were identified on the SPM in which V4 was activated. V1/V2 was identified in this experiment, and the coordinates were confirmed on the SPM from the second experiment (see Table 2).

- Talairach coordinates are stated as $\mathrm{mm} x, y, z$ from the anterior ACPC line and correspond to the stereotactic conventions of the atlas of Talairach and Tournoux (1988).

* Score not significant at $p<0.05$, corrected for multiple comparisons.

shown that the use of attention directed to a specific visual submodality, at least for shape and color, activates many areas, including the areas defined in our present and previous study (Lueck et al., 1989). This implies that precise localization of the perception of attributes of vision cannot be adequately demonstrated when factors such as attention are added to appropriate visual stimulation. The use of more sophisticated stimuli may, in the future, give us insights into the nature and role of the target projection fields of V4 and V5 in human vision.

\section{Area V1 (the striate cortex)}

Not surprisingly, area V1 was active in all our experiments when the eyes were open. The spatial resolution of the scanner was not high enough to determine its boundaries with the precision possible with Nissl- or myelin-stained sections. It is interesting that the increase in activity in $\mathrm{V} 1$ was higher in the motion study, regardless of whether the "motion" stimulus was moving or stationary (Table 2). Why this should be so is not entirely clear. The pattern of random small black dots contained many more boundaries of higher contrast than the 15 rectangles forming the color Mondrian, and the total luminance of the 2 displays was not equivalent. It might therefore have been a more powerful stimulus for a visual area that contains many more orientation-selective than wavelength-selective cells. This explanation derives some support from the observation that the presence of motion in the stimulus gave rise only to a minimal increase in striate $\mathrm{rCBF}$.

\section{Area 12}

While we have been able to demonstrate unambiguously that V4 and V5 are 2 separate, functionally specialized visual areas, we were unsuccessful in distinguishing between areas $\mathrm{V} 1$ and V2. We suppose that the area of high activity at the occipital pole found in all our scans represents area V2 in addition to V1. The human studies of Burkhalter and Bernardo (1989) show that, as in the macaque, V2 surrounds V1 and is connected to it. There are 2 major difficulties in separating the 2 areas. One is the current spatial resolution of PET studies, and the other
Table 2. Experiment 2: motion versus static

\begin{tabular}{|c|c|c|c|c|c|}
\hline \multirow[b]{2}{*}{ Region } & \multicolumn{3}{|c|}{$\begin{array}{l}\text { CBF (adjusted group } \\
\text { means; } \mathrm{ml} \mathrm{dl}^{-1} \min ^{-1} \text { ) }\end{array}$} & \multirow{2}{*}{$\begin{array}{l}\text { Talairach } \\
\text { coordinates }^{4}\end{array}$} & \multirow[b]{2}{*}{$Z$ score } \\
\hline & Rest & Static & Motion & & \\
\hline Right V4 & 61 & 66 & 66 & & \\
\hline Left V4 & 64 & 66 & 64 & & \\
\hline Mean & 63 & 66 & 65 & & \\
\hline Right V5 & 49 & 48 & 52 & $+38,-62,+8$ & 5.58 \\
\hline Left V5 & 47 & 49 & 53 & $-38,-74,+8$ & 4.51 \\
\hline Mean & 48 & 49 & 52 & & \\
\hline $\mathrm{V} 1 / \mathrm{V} 2$ & 55 & 68 & 69 & $-4,-90,0$ & \\
\hline
\end{tabular}

Adjusted group mean rCBF for each condition (averaged from 2 estimations for each of the 3 physiological states) in the areas indicated in the SPMs to have shown significant rCBF range (at $p<0.05$ level) for motion versus static. Flow values have been normalized by ANCOVA to a mean flow of $50 \mathrm{ml} \mathrm{dl} / \mathrm{min}$ '. Loci were identified on the SPM in which V5 was activated. VI/V2 was identified in the first experiment (see Table 1), and the coordinates were confirmed on the SPM from this experiment.

a Talairach coordinates are stated as mm $x, y, z$ from the anterior end of the ACPC line and correspond to the stereotactic conventions of the atlas of lalairach and Tournoux (1988).

is that both areas were probably active in all conditions, given that, at least in the monkey, all submodalities of vision are represented in both (Baizer et al., 1977; Zeki, 1978d; DeYoe and Van Essen, 1985; Shipp and Zeki, 1985).

Human V1 and V2 are very similar to that of the macaque in terms of cytochrome oxidase architecture (Horton and Hedley-Whyte, 1984; Burkhalter and Bernardo, 1989). However, at least in the macaque, the nature of the functional grouping is different in the 2 areas, with color and motion signals being segregated in different layers of $\mathrm{V} 1$ as opposed to different stripes in V2 (Livingstone and Hubel, 1984; DeYoe and Van Essen, 1985; Shipp and Zeki, 1985). One might therefore expect that, with higher resolution in the functional images, the differences between the 2 areas and therefore their boundaries should be resolvable. Even allowing for the limited resolution of our PET SPMs, the region of high activity in the posterior part of the occipital lobe is too widespread to be confined to V1 (Fig. 1). This suggests that a visual area adjoining $\mathrm{V} 1$, located in the lingual gyrus inferiorly and the cuneus superiorly, is active in addition to $\mathrm{V} 1$, and we suppose that part of this area corresponds to human V2.

\section{Functional connections of human visual cortex: parallel outputs from area VI to areas V4 and V5 in the human hrain}

Confidence that the areas we have demonstrated are visual in function is supported by the fact that their rCBF covaried consistently with $\mathrm{rCBF}$ changes in the striate cortex. This contrasted with other areas, for example, the primary motor cortex, whose rCBF did not covary systematically with V1/V2. Covariation between areas must indicate a functional and hence anatomical connection between them, either directly or through intervening areas, which would then also be expected to covary with the others. This method of analysis may therefore be used to provide powerful, though indirect, evidence of functional anatomical connections in the normal human brain.

Anatomical evidence in the macaque monkey shows that VI is connected with V5, both directly (Zeki, 1969, 1971; Lund et al., 1975) and through V2 (Leki, 197l; Shipp and Zeki, 1985, $1989 \mathrm{a}, \mathrm{b}) . \mathrm{V} 1$ is also connected with V4. This connection is 
mainly through V2 (Zeki, 1971; DeYoe and Van Essen, 1985; Shipp and Zeki, 1985; Zeki and Shipp, 1989), but there is also a direct output to V4 from the foveal representation in V1 (Zeki, 1978 b; Yukie and Iwai, 1985). Compatible with this is the finding that, during motion stimulation, V1/V2 covaries with V5, and during color stimulation, it covaries with $\mathrm{V} 4$. In addition to demonstrating indirectly the connections between V1/V2 and these 2 areas, the results show that, as in the macaque monkey, the outputs must be in parallel, because V4 was not active in the motion study, nor was V5 in the color study.

The demonstration of parallel outputs from the monkey striate cortex led to the conclusion that V1 must act as a segregator, parceling out different signals to different prestriate areas (Zeki, 1975), a conclusion since confirmed (Livingstone and Hubel, 1984). In a similar way, our demonstration of parallel outputs from human $\mathrm{V} 1 / \mathrm{V} 2$ leads to the conclusion that $\mathrm{V} 1 / \mathrm{V} 2$ of the human brain also acts functionally as a segregator. This is a safe conclusion because it is based on a large body of anatomical results from the monkey visual cortex. The importance of the demonstration of this similarity in the organization of monkey and human brain lies in the fact that, by analogy, one may be able to make predictions about other, as yet uncharted, human cortical areas, just as predictions about the internal functional organization of areas in monkeys can be made by studying their anatomical connections (Zeki and Shipp, 1988; Zeki, 1990b). A second conclusion is that there is much information in the PET scans from which one can make functional and anatomical deductions.

In summary, a detailed analysis of the PET data reported here allows us to demonstrate parallelism in the human visual cortex and to infer connections between the visual areas. This goes well beyond our initial aim to obtain direct evidence for functional specialization in human visual cortex. We had no notion when we started of how rich a source of information such noninvasive studies could be, especially when coupled with detailed knowledge gained from experimental studies in primates. The success of the approach encourages us to use the method extensively to inquire more deeply into the strategies used by the cerebral cortex to construct the visual image in the human brain.

\section{References}

Anstis S, Cavanagh P (1983) A minimum motion technique for judging equiluminance. In: Colour vision (Mollon JD, Sharpe LT, eds), pp 155-166. London: Academic.

Baizer JS, Robinson DL, Dow BM (1977) Visual responses of area 18 neurons in awake, behaving monkey. J Neurophysiol 40:10241037.

Broca PP (1861) Perte de la parole, ramollissement chronique et destruction partielle du lobe antérieur gauche du cerveau. Bull Soc Anthropol (Paris) 2:235.

Burkhalter A, Bernardo KL (1989) Organization of cortico-cortical connections in human visual cortex. Proc Natl Acad Sci USA 86: 1071-1075.

Carney T, Shadlen M, Witskes E (1987) Parallel processing of motion and colour information. Nature 328:647-649.

Corbetta M, Miezin FM, Dobmeyer S, Shulman GL, Petersen SE (1990) Attentional modulation of neural processing of shape, color, and velocity in humans. Science 248:1556-1559.

Cragg BG (1969) The topography of the afferent projections in circumstriate visual cortex (C.V.C.) of the monkey studied by the Nauta method. Vision Res 9:733-747.

Cunningham VJ, Deiber M-P, Frackowiak RSJ, Friston KJ, Kennard C, Lammertsma AA, Lueck CJ, Romaya J, Zeki S (1990) The motion area (area V5) of human visual cortex. J Physiol (Lond) 423: $101 P$
Damasio A (1985) Disorders of complex visual processing: agnosias, achromatopsia, Balint's syndrome, and related difficulties of orientation and construction. In: Principles of behavioral neurology (Mesulam MM, ed), pp 259-288. Philadelphia: Davis.

Damasio A, Yamada T, Damasio H, Corbett J, McKee J (1980) Central achromatopsia: behavioral, anatomic and physiologic aspects. Neurology 30:1064-1071.

Desimone R, Ungerleider LG (1986) Multiple visual areas in the caudal superior temporal sulcus of the macaque. J Comp Neurol 248 164-189.

DeYoe EA, Van Essen DC (1985) Segregation of efferent connections and receptive field properties in visual area $\mathrm{V} 2$ of the macaque. Nature 317:58-61.

Duke-Elder S (1971) A system of ophthalmology, Vol 12. London: Churchill.

Fox PT, Miutum MA, Raichle ME, Miezin FM, Allman JM, Van Essen DC (1986) Mapping human visual cortex with positron emission tomography. Nature 323:806-809.

Friston KJ, Passingham RE, Nutt JG, Heather JD, Sawle GV, Frackowiak RSJ (1989) Localization in PET images: direct fitting of the intercommissural (AC-PC) line. J Cereb Blood Flow Metab 9:690 695.

Friston KJ, Frith CD, Liddle PF, Dolan RJ, Lammertsma AA, Frackowiak RSJ (1990) The relationship between global and local changes in PET scans. J Cereb Blood Flow Metab 10:458-466.

Fritsch G, Hitzig E (1870) Über die elektrische Erregbakeit des Grosshirns. Arch Anat Physiol Wiss Med 37:300-332.

Henschen SE (1930) Pathologie des Gehirns. 8, Stockholm.

Holmes $\mathrm{G}$ (1918) Disturbances of vision by cerebral lesions. $\mathrm{Br} \mathrm{J}$ Ophthalmol 2:253-285.

Holmes G (1945) The Ferrier Lecture: the organization of the visual cortex in man. Proc R Soc Lond [Biol] 132:348-361.

Horton JC, Hedley-Whyte ET (1984) Mapping of cytochrome oxidase patches and ocular dominance columns in human visual cortex. Philos Trans R Soc Lond [Biol] 304:255-272.

Kolmel H (1988) Pure homonymous hemiachromatopsia. Eur Arch Psychiatry Neurol Sci 237:237-243.

Komatsu H, Wurtz RH (1988) Relation of cortical areas MT and MST to pursuit eye movements. I. Localization and visual properties of neurons. J Neurophysiol 60:580-603.

Lammertsma AA, Cunningham VJ, Deiber M-P, Heather JD, Bloomfield PM, Nutt J, Frackowiak RSJ, Jones T (1990) Combination of dynamic and integral methods for generating reproducible functional CBF images. J Cereb Blood Flow Metab 10:675-686.

Land EH (1974) The retinex theory of colour vision. Proc R Inst Gr Brit 47:23-58.

Lashley KS (1931) Mass action in cerebral function. Science 73:245254.

Lenz G (1921) Zwei Sektionsfalle doppelseitiger zentraler Farbenhemianopsia. Z Ges Neurol Psychiatr 71:135-186.

Livingstone MS, Hubel DH (1984) Anatomy and physiology of a color system in primate visual cortex. J Neurosci 4:309-356.

Lueck CJ, Zeki S, Friston KJ, Deiber M-P, Cope P, Cunningham VJ, Lammertsma AA, Kennard C, Frackowiak RSJ (1989) The colour centre in the cerebral cortex of man. Nature 340:386-389.

Lund JS, Lund RD, Hendrickson AE, Bunt AH, Fuchs AF (1975) The origin of efferent pathways from the primary visual cortex (area 17) of the macaque as shown by the retrograde transport of horseradish peroxidase. J Comp Neurol 164:287-304.

Mackay G, Dunlop JC. (1899) The cerebral lesions in a case of complete acquired colour blindness. Scott Med Surg J 5:503-512.

Miezin FM, Fox PT, Raichle ME, Allman JM (1987) Localized responses to low contrast moving random dot patterns in human visual cortex monitored with positron emission tomography. Soc Neurosci Abstr 13:631.

Monbrun A (1939) Les affections des voies optiques rétrochiasmatiques et de l'écorce visuelle. In: Traité d'ophthalmologie, pp 903905. Paris: Masson et Cie.

Pearlman AL, Birch J, Meadows JC (1979) Cerebral color blindness: an acquired defect in hue discrimination. Ann Neurol 5:253-261.

Ramachandran VS (1987) Interaction between colour and motion in human vision. Nature 328:645-647.

Ramachandran VS, Gregory RL (1978) Does colour provide an input to human motion perception? Nature 275:55-56.

Sacks O, Wasserman RL, Zeki S, Seigel RM (1988) Sudden color blindness of cerebral origin. Soc Neurosci Abstr 14:1251. 
Shipp S, Zeki S (1985) Segregation of pathways leading from area V2 to areas V4 and V 5 of macaque monkey visual cortex. Nature 315: 322-325.

Shipp S, Zeki S (1989a) The organization of connections between areas V1 and V5 of macaque monkey visual cortex. Eur J Neurosci 1:309332.

Shipp S, Zeki S (1989b) The organization of connections between areas V5 and V2 in macaque monkey visual cortex. Eur J Neurosci $1: 333-354$

Spinks TJ, Jones T, Gilardi MC, Heather JD (1988) Physical performance of the latest generation of commercial positron scanner. IEEE Trans Nucl Sci 35:721-725.

Talairach J, Tournoux P (1988) Co-planar stereotaxic atlas of the human brain. Stuttgart: Thieme.

Tanaka K, Hirosaka K, Saito H-A, Yukie M, Fukada Y, Iwai E (1986) Analysis of local and wide field movements in the superior temporal visual areas of the macaque monkey. J Neurosci 6:134-144.

Teuber HL, Battersby WS, Bender MB (1960) Visual field defects after penetrating missile wounds of the brain. Cambridge, MA: Harvard UP.

Thurston SE, Leigh RJ, Crawford T, Thompson A, Kennard C (1988) Two distinct deficits of visual tracking caused by unilateral lesions of cortex in humans. Ann Neurol 23:266-273.

Verrey (1888) Hémiachromatopsie droite absolue. Arch Ophthalmol (Paris) 14:422-434.

Yukie M, Iwai E (1985) Laminar origin of direct projection from area $\mathrm{VI}$ to V4 in the rhesus monkey. Brain Res 346:383-386.

Zeki SM (1969) Representation of central visual fields in prestriate cortex of the monkey. Brain Res 14:271-291.

Zeki SM (1971) Cortical projections from two prestriate areas in the monkey. Brain Res 34:19-35.

Zeki SM (1973) Colour coding in the rhesus monkey prestriate cortex. Brain Res 53:422-427.
Zeki SM (1974a) The mosaic organization of the visual cortex in the monkey. In: Essays on the nervous system (Bellairs R, Grey EG, eds.), pp 327-343. Oxford: Clarendon.

Zeki SM (1974b) Functional organization of a visual area in the posterior bank of the superior temporal sulcus of the rhesus monkey. J Physiol (Lond) 236:549-573.

Zeki SM (1975) The functional organization of projections from striate to prestriate visual cortex in the rhesus monkey. Cold Spring Harbor Symp Quant Biol 40:591-600.

Zeki SM (1977) Colour coding in the superior temporal sulcus of rhesus monkey visual cortex. Proc R Soc Lond [Biol] 197:195-223.

Zeki SM (1978a) Functional specialization in the visual cortex of the rhesus monkey. Nature 274:423-428.

Zeki SM (1978b) The cortical projections of foveal striate cortex in the rhesus monkey. J Physiol (Lond) 277:227-244.

Zeki SM (1978c) The third visual complex of rhesus monkey prestriate cortex. J Physiol (Lond) 277:245-272.

Zeki SM (1978d) Uniformity and diversity of structure and function in rhesus monkey prestriate visual cortex. J Physiol (Lond) 277:273290.

Zeki S (1980) The responses of cells in the anterior bank of the superior temporal sulcus in macaque monkeys. J Physiol (Lond) 308:35P.

Zeki S (1990a) A century of cerebral achromatopsia. Brain 113:17211777.

Zeki S (1990b) The motion pathways of the visual cortex. In: Vision: coding and efficiency (Blakemore $\mathrm{C}$, ed), pp 321-345. Cambridge: Cambridge UP.

Zeki S, Shipp S (1988) The functional logic of cortical connections. Nature 335:311-317.

Zeki S, Shipp S (1989) Modular connections between areas V2 and V4 of macaque monkey visual cortex. Eur J Neurosci 1:494-506.

Zihl J, von Cramon D, Mai N (1983) Selective disturbance of movement vision after bilateral brain damage. Brain 106:313-340. 